\title{
ANALISIS ZONA BAHAYA BANJIR DAN TSUNAMI BERBASIS EKOREGION DI PROVINSI BANTEN
}

\section{Analysis of Flood and Tsunami Hazards Based on Ecoregion in Banten Province}

\author{
Zulham Husein'1)*, Boedi Tjahjono²) dan Nurwajedi3) \\ 1) Program Studi Mitigasi Bencana dan Kerusakan Lahan, Sekolah Pascasarjana IPB, Jl. Meranti Kampus IPB \\ Dramaga, Bogor 16680 \\ 2) Departemen Ilmu Tanah dan Sumberdaya Lahan, Fakultas Pertanian IPB, J1. Meranti Kampus IPB Dramaga, \\ Bogor 16680 \\ 3) Badan Informasi Geospasial, J1. Raya Jakarta - Bogor KM 46, Cibinong Bogor
}

\begin{abstract}
Ecoregion is a characteristic of a region which commonly used to assess the potency of land. The objective of this study is to see how far the ecoregion analysis can be used to predict susceptibility zones of flood and tsunami disaster in Banten Province. The ecoregion-based determination of susceptibility zones was analyzed using Analytical Hierarchy Process $(A H P)$ which is implemented in terms of geoindicator weights and scores. In this study, selected geoindicator was extracted by ecoregion frames. The next step is determining the hazard zone through the parametric approach, where each disaster used different parameters. The results of AHP analysis shows that landforms are the most influential geoindicators in assessing susceptibility zones. The landform geoindicator's weight in flood and tsunami disaster are 0.678 and 0.605. Otherwise, the ecosystem geoindicators and vegetation communities weight in floods are 0.150 and 0.173 , while for tsunami disaster, their weight are 0.157 and 0.237. Furthermore, the results flood susceptibility were tested using kappa accuracy, and the result showed more than $81 \%$ correlation between the analysis result and the existing condition. Otherwise, on the hazard analysis showed the accuracy less than 80\%. The results of ecoregion-based analysis of disaster susceptibility can be used as additional information for local government to develop disaster-based areas, considering Indonesia is the one of the most country with high disaster potential.
\end{abstract}

Keywords: Ecoregion, flood, landform, susceptibility, tsunami

\section{ABSTRAK}

Ekoregion merupakan karakteristik penciri wilayah yang biasa digunakan untuk menilai potensi lahan. Tujuan dari penelitian ini adalah untuk melihat sejauh mana ekoregion dapat digunakan untuk menilai kerentanan zona bencana banjir dan tsunami di Provinsi Banten. Penentuan zona kerentanan berbasis ekoregion dilakukan menggunakan Analytical Hierarchy Process (AHP) yang diimplementasikan dalam bobot dan skor geoindikator. Geoindikator terpilih dalam penelitian ini merupakan hasil ekstraksi dari faktor pembentuk ekoregion. Langkah selanjutnya adalah penilaian zona bahaya berdasarkan kelas kerawanan (susceptibility) sedang sampai sangat tinggi menggunakan pendekatan parametrik. Hasil AHP menunjukkan bahwa bentuk lahan merupakan geoindikator yang paling berpengaruh dalam penilaian zona kerawanan. Bobot geoindikator bentuklahan pada bencana banjir dan tsunami adalah 0.678 dan 0.605 . Sementara geoindikator ekosistem dan komunitas vegetasi untuk banjir bobotnya masing-masing adalah 0.150 dan 0.173 , sedangkan untuk bencana tsunami, bobotnya masingmasing adalah 0.157 dan 0.237 . Hasil analisis kerentanan banjir selanjutnya diuji dengan menggunakan indeks akurasi Kappa. Hasilnya menunjukkan korelasi lebih dari $81 \%$ antara hasil analisis dan kondisi eksisting. Adapun, uji akurasi analisis bahaya menunjukkan akurasi kurang dari $80 \%$. Hasil analisis kerentanan bencana berbasis ekoregion dapat dimanfaatkan sebagai dasar pengembangan kawasan berbasis bencana, mengingat Indonesia adalah salah satu negara dengan potensi bencana alam tinggi.

Kata kunci: Ekoregion, banjir, bentuklahan, kerawanan, tsunami

\section{PENDAHULUAN}

Pertumbuhan ekonomi Provinsi Banten telah mengalami peningkatan yang cukup signifikan, baik dari sektor industri, pariwisata, maupun pertanian. Pertumbuhan Industri Manufaktur level besar dan sedang di tahun 2015 menunjukkan terjadinya kenaikan sebesar 2.26 persen dibandingkan dengan tahun 2014. Sementara itu untuk sektor pariwisata, Tingkat Penghunian Kamar (TPK) hotel berbintang pada Desember 2015 mencapai 59.22 persen atau naik 2.73 persen dibandingkan dengan bulan sebelumnya, yaitu sebesar 56.49 persen (BPS 2015). Pencapaian angka-angka tersebut tidak lepas dari pelaksanaan dan pengembangan isu-isu strategis yang tertuang dalam Rencana Pembangunan Jangka Panjang Daerah (RPJPD) dan Rencana Pembangunan Jangka Menengah Daerah (RPJMD) Provinsi Banten. Seperti diketahui, kebijakan RPJPD dan RPJMD disusun berdasarkan amanat Undang-Undang 32 Tahun 2009 tentang Perlindungan dan Pengelolaan Lingkungan Hidup.

Berdasarkan amanat UU tersebut, setiap provinsi diharuskan melakukan penetapan wilayah ekoregion 
sebagai salah satu dasar untuk penetapan RPPLH (Rencana Perlindungan dan Pengelolaan Lingkungan Hidup) yang nantinya akan dijadikan sebagai acuan untuk penyusunan RPJPD dan RPJMD, sehingga ekoregion dalam perspektif ini merupakan peta tematik sentral yang sangat penting. Peta ekoregion adalah peta tematik yang tergolong baru di Indonesia yang memetakan keberagaman karakteristik ekologi bentanglahan. Peta ini telah tersedia pada skala 1:500,000 yang mencakup seluruh wilayah Indonesia (KLH, 2013). Dengan tersedianya informasi karakteristik ekologi bentanglahan pada peta ekoregion, peta tersebut dapat dimanfaatkan antara lain untuk analisis kerawanan bencana alam.

Provinsi Banten merupakan provinsi yang memiliki potensi bencana yang tinggi, karena wilayah ini sering terlanda banjir di musim hujan dan dalam sejarah juga pernah terlanda tsunami besar akibat letusan G. Krakatau pada 1883 (PVMBG, 2014). Peta ekoregion Provinsi Banten skala 1:250,000 telah ada sejak 2015 dan karenanya dapat dimanfaatkan untuk landasan berbagai kajian analisis lingkungan.

Mengingat tingginya dinamika perekonomian dan tingginya potensi bencana alam di Provinsi Banten, maka analisis kerawanan (susceptibility) bencana di wilayah ini sangat diperlukan agar perencanaan ekonomi Provinsi Banten dapat ditempatkan di wilayah yang tidak terganggu oleh bencana. Di lain pihak, ruang-ruang rawan bencana dapat dimanfaatkan sesuai dengan sifatnya.

Penelitian ini bertujuan untuk memetakan daerah rawan (susceptible) dan bahaya (hazard) bencana alam berdasarkan informasi yang dikandung dalam peta ekoregion Provinsi Banten. Jenis ancaman bencana yang dipilih dalam penelitian ini adalah banjir dan tsunami mengingat kedua jenis ancaman tersebut berpotensi untuk terulang kembali.

\section{BAHAN DAN METODE}

Penelitian dilakukan di Provinsi Banten yang secara geografis terletak antara $105^{\circ} 01^{\prime} 11^{\prime \prime}$ sampai $106^{\circ} 07^{\prime} 12^{\prime \prime}$ Bujur Timur, serta diantara $05^{\circ} 07^{\prime} 50^{\prime \prime}$ sampai $07^{\circ} 01^{\prime} 01^{\prime \prime}$ Lintang Selatan. Data yang digunakan dalam penelitian ini meliputi data primer dan data sekunder. Data primer berupa citra satelit Landsat tahun perekaman 2015 yang diperoleh dari situs USGS dan data SRTM akurasi 90 meter. Data sekunder diperoleh dengan melakukan penelusuran ke instansi pemilik data, penelusuran internet dan pelaksanaan studi pustaka berupa peta rupa bumi Indonesia (RBI), peta kemiringan lereng dan peta ekoregion dari BLHD Provinsi Banten.

\section{Konsep Dasar Pemanfaatan Peta Ekoregion untuk Kerawanan Bencana}

Analisis kerawanan bencana (banjir dan tsunami) ini dilakukan menggunakan pendekatan ekoregion sebagai mapping unit. Dalam ekoregion, terdapat komponenkomponen penyusun yang dapat digunakan sebagai informasi untuk penilaian kerawanan bencana alam. Komponen-komponen tersebut adalah bentuklahan, ekosistem, dan komunitas vegetasi yang kesemuanya akan dinilai tingkat kepentingannya dalam kaitannya dengan kerawanan bencana melalui analisis Analytical Hierarchy
Process. Nilai parameter yang diberikan diperoleh dari para ahli, sehingga nilai pada setiap parameter tersebut merupakan hasil interpetasi atau pengalaman para ahli tersebut (Othman et al., 2011). Dalam hal ini, hasil AHP akan diintegrasikan dengan SIG agar dapat memberikan informasi persebaran spasial daerah-daerah rawan bencana secara visual (Sambah dan Miura, 2014; Khodadad dan Jang, 2015; Mudin et al., 2015). Pemanfaatan peta ekoregion sebagai dasar analisis kerawanan diharapkan dapat menjadi salah satu metode sederhana yang mampu diaplikasikan dan diduplikasi dengan mudah oleh pemerintah daerah, namun tetap memiliki tingkat ketelitian yang tinggi. Dengan demikian, ekoregion tidak hanya dapat dimanfaatkan sebagai dasar penyusunanan RPJMD, RPJPD dan RTRW tetapi juga dapat digunakan sebagai dasar analisis tingkat kerawanan bencana.

\section{Zonasi Daerah Rawan Bencana Banjir dan Tsunami}

Pengertian kerawanan (susceptibility) bencana menurut UU 24 tahun 2007 adalah kondisi atau karakteristik geologis, biologis, hidrologis, klimatologis, geografis, sosial, budaya, politik, ekonomi, dan teknologi pada suatu wilayah untuk jangka waktu tertentu yang mengurangi kemampuan mencegah, meredam, mencapai kesiapan, dan mengurangi kemampuan untuk menanggapi dampak buruk bahaya tertentu. Kerawanan (susceptibility) atau kerapuhan (fragility) dalam manajemen risiko bencana atau kepekaan (sensitivity) dalam adaptasi perubahan iklim adalah kecenderungan fisik makhluk hidup, infrastruktur, dan lingkungan yang terkena dampak dari fenomena yang membahayakan yang disebabkan oleh rendahnya daya tahan dan kecenderungan masyarakat serta ekosistem untuk mengalami penderitaan/kerugian sebagai konsekuensi dari kondisi hakiki dan kondisi kontekstual yang membuatnya masuk akal jika sistem semacam itu sekali terkena dampak akan runtuh atau mengalami penderitaan dan kerusakan besar yang diakibatkan oleh pengaruh peristiwa bahaya yang terjadi. Pengertian kerawanan bencana dalam penelitian ini adalah sifat atau karakteristik dasar dari daerah atau wilayah yang tergolong rentan atau mudah mengalami suatu proses alami yang berpeluang untuk menimbulkan bencana.

Dalam penelitian ini, hasil analisis AHP merupakan hasil penilaian ahli yang direpresentasikan dalam bentuk angka yang memiliki skala perbandingan (Saaty, 1977) seperti yang disajikan pada Tabel 1. Para ahli (experts) yang dijadikan responden dalam penelitian ini ada 16 orang, yaitu 3 ahli dari Institut Pertanian Bogor (IPB), 4 ahli dari Lembaga Ilmu Pengetahuan Indonesia (LIPI), dan 9 ahli dari Pusat Vulkanologi dan Mitigasi Bencana Geologi (PVMBG). Bobot yang diperoleh kemudian dintegrasikan dengan GIS dengan metode overlay.

Hasil penilaian para ahli dinilai tingkat kekonsitenannya dengan menggunakan perhitungan Consistency Ratio (CR). Matriks perbandingan yang memiliki penilaian CR 0.10 harus dievaluasi kembali (Saaty, 1977). CR dihitung dengan menggunakan persamaan berikut (Saaty, 1977):

$$
C R=\frac{C I}{R I}
$$


Keterangan :

$\mathrm{CR}=$ Consitensy ratio

$\mathrm{CI}=$ Indeks konsistensi

$\mathrm{RI}=$ Nilai pembangkit random

Tabel 1. Nilai skala perbandingan

\begin{tabular}{|c|c|}
\hline Nilai & Keterangan \\
\hline 1 & Faktor vertikal sama penting dengan faktor horizontal \\
\hline 3 & $\begin{array}{l}\text { Faktor vertikal sedikit lebih penting dari faktor } \\
\text { horizontal }\end{array}$ \\
\hline 5 & Faktor vertikal jelas lebih penting dari faktor horizontal \\
\hline 7 & $\begin{array}{l}\text { Faktor vertikal sangat jelas lebih penting dari faktor } \\
\text { horizontal }\end{array}$ \\
\hline 9 & $\begin{array}{l}\text { Faktor vertikal mutlak lebih penting dari faktor } \\
\text { horizontal }\end{array}$ \\
\hline $\begin{array}{c}2,4,6 \\
8\end{array}$ & Apabila ragu-ragu antara dua nilai yang berdekatan \\
\hline $1 /(2-9)$ & Kebalikan dari keterangan nilai $2-9$ \\
\hline
\end{tabular}

Tingkat kerawanan bencana pada penelitian ini dihasilkan melalui proses tumpang tindih (overlay) peta tematik, yakni antara peta bentuklahan (landform), peta ekosistem, dan peta komunitas vegetasi (yang bersumber dari peta ekoregion) yang telah mempunyai bobot dan skor melalui AHP. Tingkat kerawanan tersebut diklasifikasikan menjadi 5 kelas yaitu: sangat rendah, rendah, menengah, tinggi, dan sangat tinggi dimana nilai interval untuk setiap kelas dihitung dengan menggunakan persamaan berikut (PVMBG, 2014):

$$
\text { Interval }=\frac{\text { nilai terting } i-\text { nilai terendah }}{\text { jumlah kelas }}
$$

\section{Uji Validasi Peta Rawan Bencana}

Kesesuaian hasil pada model terhadap kondisi eksisting divalidasi dengan cara menghitung akurasi nilai kappa. Nilai kappa menunjukkan tingkat keakuratan model, dimana jika kappa bernilai 0.9 atau $90 \%$ mempunyai makna bahwa zonasi wilayah rawan bencana yang dihasilkan dalam pemodelan terhadap kejadian existing saling bersesuaian sebesar $90 \%$. Persamaan nilai akurasi kappa yang digunakan adalah sebagai berikut (Foody, 2002):

$$
K_{h a t}=\frac{N \sum_{i=1}^{r} x_{i i}-\sum_{i=1}^{r}\left(x_{i+} \times x_{+i}\right)}{N^{2}-\sum_{i=1}^{r}\left(x_{i+} \times x_{+i}\right)}
$$

dimana

$$
\begin{array}{lll}
\mathrm{X}_{+\mathrm{i}} & : & \text { Jumlah titik hasil klasifikasi pada kelas ke-i } \\
\mathrm{X}_{\mathrm{i+}} & : \text { Jumlah titik referensi pada kelas ke-i } \\
\mathrm{X}_{\mathrm{ii}} & : \text { Jumlah titik referensi yang sesuai dengan hasil } \\
& & \text { klasifikasi } \\
\mathrm{i} & : & \text { Baris atau kolom } \\
\mathrm{r} & : & \text { Jumlah kelas bencana } \\
\mathrm{N} & : & \text { Jumlah keseluruhan titik referensi } \\
\mathrm{K}_{\text {hat }} & : & \text { Nilai akurasi kappa }
\end{array}
$$

\section{Zonasi Daerah Bahaya Bencana Banjir dan Tsunami}

Pengertian bahaya (hazard) bencana menurut UU 24 tahun 2007 lebih mengarah pada ancaman bencana yang berarti suatu kejadian atau peristiwa yang bisa menimbulkan bencana. Bahaya adalah suatu kemungkinan kejadian di masa depan baik yang disebabkan oleh kejadian fisik alami maupun oleh manusia yang mempunyai efek merugikan pada elemen yang rentan dan terpapar. Pengertian bahaya bencana dalam penelitian ini adalah potensi atau peluang terjadinya suatu proses alami dalam waktu dekat dari suatu area yang berpeluang dapat menimbulkan bencana.

\section{Geoindikator Banjir}

Penilaian bahaya banjir merupakan kelanjutan dari penilaian kerawanan banjir. Dalam hal ini daerah yang dinilai tingkat bahayanya diambil hanya dari daerah yang mempunyai tingkat kerawanan "sedang" sampai "sangat tinggi." Dengan demikian pada daerah-daerah yang mempunyai tingkat kerawanan ini dinilai lebih jauh berdasarkan parameter tertentu, yakni berdasarkan sejarah kejadian banjir yang dikombinasikan dengan elevasi lokal dan parameter lain berupa indeks kebasahan wilayah (Topographic Wetness Index/TWI). Data sejarah banjir diperoleh dari hasil survei lapangan dan juga dari data sekunder berupa titik-titik kejadian banjir dari BNPB. Tabel 2 menyajikan rincian nilai dari geoindikator banjir, sedangkan Tabel 3 menyajikan matriks penilaian bahaya banjir berdasar Tabel 2. Dalam penelitian ini, nilai TWI dibagi ke dalam 3 kelas. Nilai TWI tertinggi menandakan bahwa wilayah tersebut secara morfologi berada pada cekungan yang berarti memiliki tingkat bahaya tinggi, sementara nilai TWI terendah menandakan bahwa wilayah tersebut berada pada punggung-punggung bukit yang berarti memiliki tingkat bahaya rendah. Adapun geoindikator elevasi digeneralisasi menjadi elevasi yang pernah mengalami banjir dan elevasi yang belum pernah

\begin{tabular}{|c|c|c|}
\hline Geoindikator & Tingkat Bahaya & Klasifikasi \\
\hline \multicolumn{3}{|l|}{$\begin{array}{l}\text { Topographic Wetness } \\
\text { Index }\end{array}$} \\
\hline $1.5-11.7$ & Tinggi & TWI 1 \\
\hline$-8.7-1.5$ & Sedang & TWI 2 \\
\hline$-18.9-(-8.7)$ & Rendah & TWI 3 \\
\hline Geoindikator & $\begin{array}{c}\text { Klasifikasi } \\
\text { (Sejarah) }\end{array}$ & $\begin{array}{c}\text { Frekuensi } \\
\text { Banjir/tahun }\end{array}$ \\
\hline \multicolumn{3}{|l|}{ Elevasi } \\
\hline$<100 \mathrm{~m}$ & Pernah terjadi banjir & $\geq 2$ kali \\
\hline$<100 \mathrm{~m}$ & $\begin{array}{l}\text { Belum pernah terjadi } \\
\text { banjir }\end{array}$ & - \\
\hline $100-300 \mathrm{~m}$ & Pernah terjadi banjir & $\geq 2$ kali \\
\hline $100-300 \mathrm{~m}$ & $\begin{array}{l}\text { Belum pernah terjadi } \\
\text { banjir }\end{array}$ & - \\
\hline$>300 \mathrm{~m}$ & Pernah terjadi banjir & $\geq 2$ kali \\
\hline$>300 \mathrm{~m}$ & $\begin{array}{l}\text { Belum pernah terjadi } \\
\text { banjir }\end{array}$ & - \\
\hline
\end{tabular}
mengalami banjir. Pengklasifikasian elevasi ini ditentukan berdasarkan titik kejadian banjir di lapangan, baik dari titik survei maupun dari titik kejadian banjir yang berasal dari Badan Nasional Penanggulangan Bencana (BNPB) periode 2012 - 2016. Khusus untuk wilayah yang secara aktual sering mengalami banjir akan tetapi tidak ter-cover dalam hasil analisis kerawanan tetap dipertimbangkan dalam analisis bahaya.

Tabel 2. Klasifikasi nilai geoindikator banjir

Tabel 3. Matriks klasifikasi tingkat bahaya banjir

\begin{tabular}{lllll}
\hline \multirow{2}{*}{ Klasifikasi } & \multicolumn{3}{l}{ Topographic Wetness Index (TWI) } \\
\cline { 3 - 5 } & TWI 3 & TWI 2 & TWI 1 \\
\hline $\overrightarrow{5}$ & Pernah terjadi banjir & Sedang & Tinggi & Tinggi \\
$\overline{\vec{a}}$ & & & \\
$\frac{0}{\bar{\Delta}}$ & Belum pernah terjadi banjir & Rendah & Rendah & Rendah \\
\hline
\end{tabular}




\section{Geoindikator Tsunami}

Bahaya tsunami (tsunami hazard) umumnya dinilai berdasarkan tingginya run up dan seberapa jauh pengaruh gelombang mencapai daratan. Dengan demikian geoindikator yang dipilih untuk penilaian bahaya tsunami dalam penelitian ini adalah kelerengan dan jarak dari garis pantai sebagai modifikasi dari parameter Cankaya et al. (2016) yang mencakup jarak dari garis pantai, elevasi, dan kelerengan. Adapun penentuan jarak terjauh dari garis pantai dalam penelitian ini mengacu pada data global historical tsunami database untuk kejadian tsunami di Indonesia, yaitu mencapai jarak 5,000 meter mengacu pada kejadian tsunami Provinsi Aceh tahun 2004 (NGDC/WDS, 2016). Adapun jarak maksimum terdekat di adaptasi dari kejadian tsunami Kabupaten Pangandaran tahun 2009 yaitu sejauh 1,500 meter. Selanjutnya pengkalsifikasian tingkat bahaya tsunami didasarkan pada klasifikasi jarak dari garis pantai dan kemiringan lereng seperti yang disajikan pada Tabel 4 dan Tabel 5.

Tabel 4. Klasifikasi nilai geoindikator tsunami

\begin{tabular}{lcc}
\hline \multicolumn{1}{c}{ Geoindikator } & Tingkat Bahaya & Klasifikasi \\
\hline Jarak dari garis pantai & & \\
\hline $0-1,500 \mathrm{~m}$ & Tinggi & Jarak dekat \\
$1,500-3,000 \mathrm{~m}$ & Sedang & Jarak menengah \\
$3,000-5,000 \mathrm{~m}$ & Rendah & Jarak jauh \\
\hline Kelerengan & & \\
\hline $0-8 \%$ & Tinggi & Landai \\
$8-15 \%$ & Sedang & Agak Landai \\
$15-25 \%$ & Rendah & Berbukit \\
$25-45 \%$ & Rendah & Berbukit \\
$>45 \%$ & Rendah & Berbukit \\
\hline
\end{tabular}

Tabel 5. Matriks klasifikasi tingkat bahaya tsunami

\begin{tabular}{|c|c|c|c|c|}
\hline \multirow{2}{*}{\multicolumn{2}{|c|}{ Klasifikasi }} & \multicolumn{3}{|c|}{ Jarak Garis Pantai } \\
\hline & & Jarak Dekat & Jarak Menengah & Jarak Jauh \\
\hline \multirow{3}{*}{ 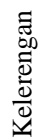 } & Landai & Tinggi & Tinggi & Sedang \\
\hline & Agak Landai & Tinggi & Sedang & Sedang \\
\hline & Berbukit & Sedang & Sedang & Rendah \\
\hline
\end{tabular}

\section{HASIL DAN PEMBAHASAN}

\section{Penilaian Geoindikator Rawan Bencana Menggunakan Metode AHP}

Berdasarkan hasil analisis matriks perbandingan berpasangan dari AHP dapat diketahui bahwa geoindikator yang paling berpengaruh terhadap penentuan zona rawan banjir dan tsunami berbasis ekoregion adalah bentuklahan (Tabel 6). Bentuklahan menunjukkan bobot yang paling tinggi jika dibandingkan dengan geoindikator ekosistem dan komunitas vegetasi, yaitu 0.678 untuk banjir dan 0.605 untuk tsunami.

Hasil pendapat dari para ahli ini sejalan dengan banyaknya pemanfaatan bentuklahan untuk analisis daerah rawan bencana oleh beberapa peneliti. Santangelo et al. (2011) melakukan karakterisasi bentuklahan kipas alluvial untuk menilai tingkat kerawanan bencana banjir di daerah perkotaan. Sementara pada tahun 2015, Chaturvedi et al. (2015) memanfaatkan karakteristik bentuklahan dataran fluvial Sungai Gangga untuk menilai daerah rawan banjir. Bentuklahan merupakan salah satu objek kajian dari geomorfologi yang sudah sering digunakan untuk memahami dan menganalisis kerawanan bencana alam seperti banjir, longsor, gempa bumi, dan bencana vulkanik (Ayala, 2002). Hal ini disebabkan karena bentuklahan mampu memberikan informasi mengenai wilayah yang memiliki probabilitas kejadian bencana tinggi berdasarkan proses pembentukannya, misalnya dataran fluvial yang terbentuk akibat pergerakan air permukaan (fluvial) yang dapat mengindikasikan dataran rawan banjir.

Tabel 6. Bobot geoindikator pembentuk banjir dan tsunami berbasis ekoregion

\begin{tabular}{llll}
\hline \multirow{2}{*}{ No } & \multirow{2}{*}{ Geoindikator } & \multicolumn{2}{c}{ Bobot } \\
\cline { 3 - 4 } & & Banjir & Tsunami \\
\hline 1 & Bentuklahan & 0.678 & 0.605 \\
2 & Ekosistem & 0.150 & 0.157 \\
3 & Komunitas Vegetasi & 0.173 & 0.237 \\
\hline Sumber: & hasil analisis AHP, 2017 & &
\end{tabular}

\section{Persebaran Daerah Rawan Banjir di Provinsi Banten}

Zona rawan banjir di lokasi penelitian dibagi kedalam 5 kelas kerawanan. Dari hasil analisis didapatkan bahwa $66.80 \%$ dari wilayah penelitian atau seluas $632,800.5$ ha tergolong ke dalam zona rawan sangat rendah. Sementara itu zona rawan banjir rendah memiliki luas $113,883.5$ ha $(12.02 \%)$ dan zona rawan banjir menengah hingga sangat tinggi mencapai 200,649 ha $(20.80 \%)$. Secara spasial, sebaran zona rawan bencana banjir pada lokasi penelitian disajikan pada Gambar 1a, sedangkan karakteristik ekoregion pada kelas kerawanan sangat tinggi disajikan pada Tabel 7. Peta kerawanan banjir berbasis ekoregion ini merupakan gambaran karakteristik betanglahan yang secara ekologis wilayah yang diliput mudah mengalami kejadian banjir. Dengan demikian informasi ini dapat digunakan oleh para pihak sebagai bahan pertimbangan terutama untuk pengembangan wilayah, mengingat sebaran zona rawan banjir kelas menengah sampai tinggi di wilayah penelitian sebagian besar tersebar di wilayah yang memiliki perkembangan ekonomi yang cukup tinggi, sehingga pemanfaatan zona rawan banjir kelas ini perlu dilakukan dengan mempersiapkan bentuk-bentuk mitigasi dan adaptasi dengan probabilitas bencana yang ada.

Tabel 7. Karakteristik ekoregion pada kelas rawan banjir sangat tinggi

\begin{tabular}{llr}
\hline Karakteristik Ekoregion & Ha & $\% *$ \\
\hline Bentuklahan & & \\
\hline Dataran Fluvio Marin & $22,726.62$ & 53.09 \\
Lembah Sungai Utama (river valey) & $20,081.38$ & 46.91 \\
\hline Ekosistem & \\
\hline Vegetasi Rawa Air Tawar Pamah & $42,808.01$ & 100.0 \\
\hline Komunitas Vegetasi & $42,808.01$ \\
\hline Hutan Tepi Sungai (Riparian) Pamah & $42,808.01$ \\
\hline Luas Total &
\end{tabular}

Bencana banjir merupakan bencana yang sering terjadi pada wilayah yang relatif datar dengan curah hujan yang tinggi dan mempunyai sistem drainase yang kurang baik. Merujuk dari hasil yang diperoleh, zona yang paling berpotensi mengalami banjir berada pada bentuklahan 
dataran fluvial, dataran fluvio-marin dan lembah sungai dengan tipe ekosistem vegetasi rawa air tawar pamah dan komunitas vegetasi hutan terna rawa air tawar dan hutan tepi sungai (riparian) pamah.

Dataran fluvial dan lembah sungai umumnya terbentuk akibat aktivitas air permukaan, baik yang terkonsentrasi maupun yang di permukaan sehingga mengakibatkan proses-proses erosi, transportasi, dan deposisi. Hal ini sesuai dengan karakter kedua bentuklahan yang mempunyai kondisi topografi dataran rendah (dataran fluvial) dan cekungan untuk lembah sungai (Sriyono, 2014), sehingga sangat memungkinkan aliran air permukaan terakumulasi pada bentuklahan ini dan menimbulkan banjir. Sementara itu ekosistem vegetasi rawa air tawar pamah merupakan vegetasi yang persebarannya menempati kawasan-kawasan yang digenangi secara periodik atau permanen. Adapun komunitas vegetasi hutan terna rawa air tawar pamah dan hutan tepi sungai pamah merupakan bagian dari ekosistem ini (Kartawinata, 2013). Dengan demikian, geoindikator bentuklahan, ekosistem, dan komuntas vegetasi dapat dijadikan sebagai penciri zona rawan banjir, karena mampu memberikan informasi mengenai probabilitas pergerakan dan akumulasi air permukaan.

\section{Uji Validasi Peta Rawan Banjir}

Sebaran spasial kelas rawan bencana yang telah diperoleh diharapkan dapat memberikan informasi tambahan bagi pemerintah atau para pihak dalam melakukan pengembangan wilayah. Dari hasil perhitungan akurasi, pemodelan peta rawan bencana ini memiliki nilai Kappa sebesar 0.81 yang berarti bahwa model pemetaan ini memiliki tingkat akurasi yang tinggi yaitu sebesar $81 \%$. Landis dan Koch (1977) juga mengemukakan bahwa nilai kappa antara 0.81 sampai 1.00 masuk kedalam kategori akurasi tinggi.

\section{Persebaran Daerah Rawan Tsunami di Provinsi Banten}

Dari hasil analisis kerawanan tsunami di wilayah penelitian, didapatkan bahwa luas zona rawan tsunami "sangat tinggi" hanya seluas $24,186.13$ ha atau $2.55 \%$ dari luas wilayah penelitian. Sementara itu zona rawan tsunami kelas "menengah" hingga "tinggi" berkisar 45,737.1 hingga $87,719.5$ ha $(4.8-9.3 \%)$. Dalam penelitian ini, karakteristik ekoregion yang digunakan untuk penentuan zona kerawanan tsunami bukan merupakan faktor pembentuk tsunami itu sendiri, melainkan karakteristik wilayah yang mudah terkena gelombang tsunami dari lautan. Informasi peta rawan tsunami ini diharapkan menjadi bahan pertimbangan dalam pengembangan wilayah, terutama pengembangan wilayah pesisir yang saat sekarang menjadi pusat destinasi wisata Provinsi Banten. Sebaran spasial zona rawan bencana tsunami hasil penelitian ini disajikan pada Gambar $1 b$, sementara itu karakteristik ekoregion pada kelas kerawanan sangat tinggi disajikan pada Tabel 8.

Mengingat bahwa tsunami dalam penelitian ini berasal dari laut, maka zona yang memiliki tingkat kerawanan tsunami paling tinggi berada di pesisir pantai dikarenakan wilayah pesisir merupakan daratan pertama yang terdampak oleh energi gelombang tsunami. Berdasarkan morfologinya, daerah pesisir dapat dibagi menjadi daerah bertebing terjal, pesisir bergisik, pesisir berawa payau, dan terumbu karang (Suharini dan Palangan, 2014). Di wilayah penelitian, zona yang memiliki potensi kerawanan tinggi lebih banyak berada pada bentuklahan dataran fluvio marin. Dataran ini merupakan dataran yang terbentuk oleh dua proses geomorfik, yaitu dari aktivitas marin dan fluvial secara intensif, terutama dari arus pasang surut air laut dan arus sungai. Pengaruh proses marin sendiri dapat berlangsung secara intensif di sepanjang garis pantai, bahkan dapat mencapai puluhan kilometer masuk ke pedalaman (Suharini dan Palangan, 2014). Oleh karena itu dataran fluvio-marin sangat cocok dijadikan sebagai penciri untuk zona rawan tsunami. Dilihat dari karakteristik ekosistem, zona rawan tsunami pada daerah penelitian lebih bervariasi daripada zona rawan banjir, yakni mencakup ekosistem vegetasi air masin, vegetasi rawa air tawar pamah, dan vegetasi darat yang tumbuh berkembang pada gradasi elevasi 0-1,000 meter (Kartawinata, 2013), sedangkan untuk ekosistem vegetasi air masin dan sebagian ekosistem rawa air tawar pamah masih dipengaruhi oleh aktifitas pasang surut air laut. Untuk peta kerawanan dan bahaya tsunami tidak dilakukan uji akurasi kappa karena tidak adanya informasi kejadian bencana terbaru di lokasi penelitian.

Tabel 8. Karakteristik ekoregion pada kelas rawan tsunami sangat tinggi

\begin{tabular}{|c|c|c|c|}
\hline \multirow{2}{*}{$\begin{array}{c}\text { Kelas } \\
\text { Kerawanan } \\
\text { Tsunami }\end{array}$} & \multirow[b]{2}{*}{ Karakteristik Ekoregion } & \multicolumn{2}{|c|}{ Luasan } \\
\hline & & ha & $\% *$ \\
\hline \multirow{8}{*}{ 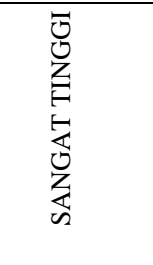 } & Bentuklahan & & \\
\hline & Dataran Fluvio Marin & $24,186.13$ & 100.00 \\
\hline & Ekosistem & & \\
\hline & Vegetasi Air Masin & $2,245.98$ & 9.29 \\
\hline & Vegetasi Air Masin Monsun & $21,940.15$ & 90.71 \\
\hline & Komunitas Vegeteasi & & \\
\hline & Hutan Mangrove & $2,193.41$ & 9.07 \\
\hline & Hutan Mangrove Monsun & $21,940.15$ & 90.71 \\
\hline Luas Total & & $24,186.13$ & \\
\hline
\end{tabular}




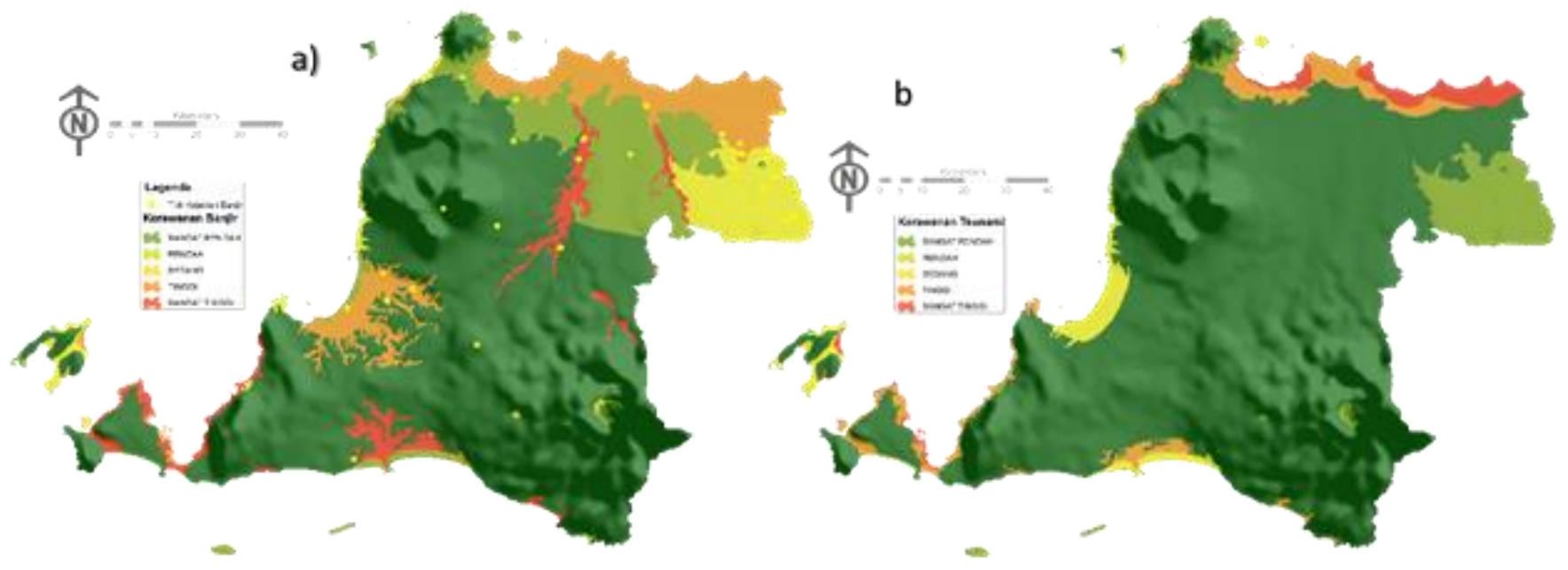

Gambar 1. a). Zona rawan banjir dan b). Zona rawan tsunami

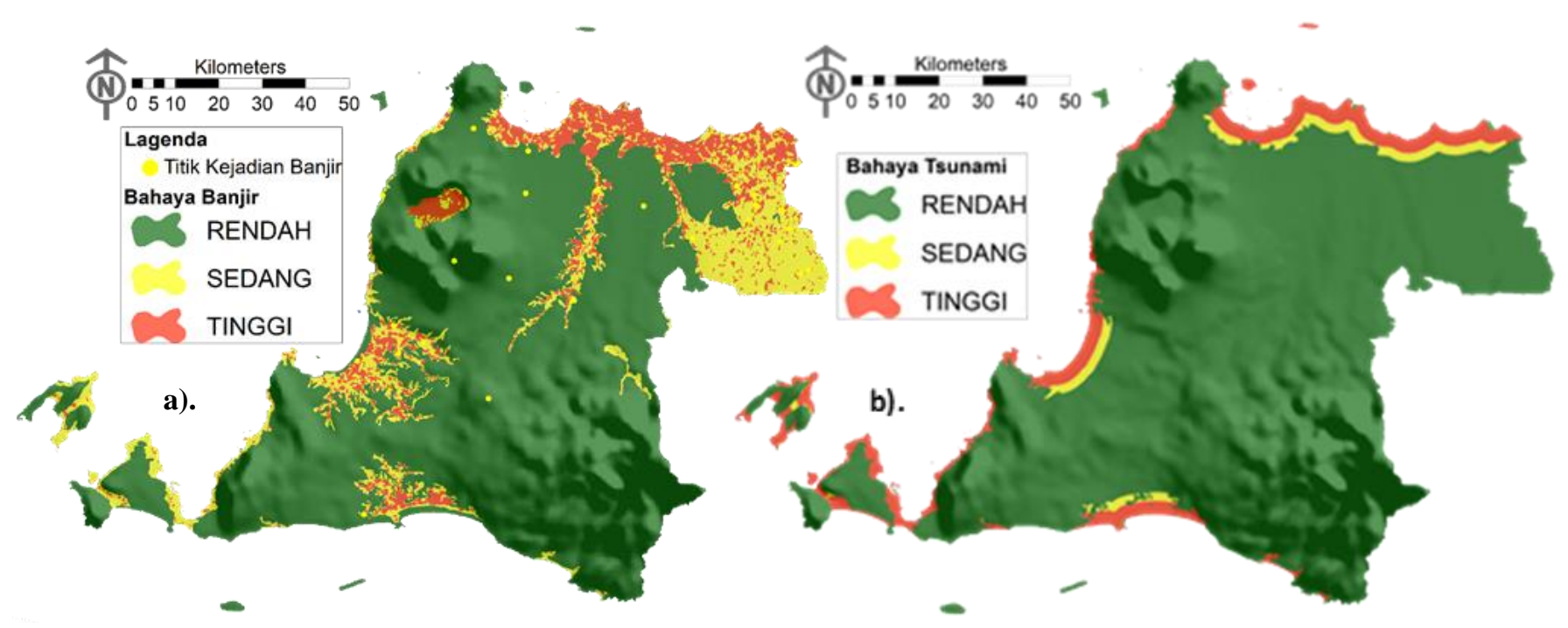

Gambar 2. a). Zona bahaya banjir dan b). Zona bahaya tsunami

\section{Persebaran Daerah Bahaya Banjir dan Tsunami di Provinsi Banten (Parametrik)}

Analisis bahaya merupakan lanjutan dari analisis kerawanan, dimana kelas kerawanan sedang hingga sangat tinggi dipertajam dengan menggunakan parameter tambahan. Dalam hal ini penilaian tingkat bahaya banjir ditentukan berdasarkan parameter sejarah kejadian banjir yang dikombinasi dengan elevasi dan besarnya nilai indeks kebasahan suatu wilayah (TWI). Indeks kebasahan sering digunakan sebagai indikator wilayah berpotensi banjir, meskipun tidak secara tegas dapat membedakan daerah rawan banjir akan tetapi dapat memberikan informasi kuantitatif kerawanan banjir pada cekungan (Aksoy et al., 2016). Pendekatan parametrik yang digunakan dalam penilaian bahaya ini bertujuan untuk mendetilkan areaarea mana yang berpotensi terkena banjir dan tsunami dalam waktu dekat. Kelas bahaya banjir dan tsunami di wilayah penelitian dibagi kedalam 3 kelas, yaitu rendah, sedang, dan tinggi. Perubahan pola sebaran pada potensi bahaya ini mengindikasikan adanya pendetilan informasi (Gambar 2a). Meskipun pendetilian informasi telah dilakukan, hasil uji akurasi kappa pada bencana banjir menunjukkan nilai yang lebih rendah dari analisis sebelumnya $(<80 \%)$. Hal ini dapat disebabkan oleh kurangnya jumlah titik validasi lapangan yang diperoleh. Sementara itu dari analisis bahaya tsunami memberikan gambaran yang lebih jelas mengenai probabilitas bahaya pada rentang jarak tertentu (Gambar 2b). Secara teoritis, wilayah pesisir utara Pulau Jawa memiliki tingkat bahaya tsunami yang lebih rendah dibandingkan dengan wilayah pesisir selatan yang berhadapan langsung dengan zona subduksi lempeng tektonik (palung laut Jawa). Namun mengingat bahwa sejarah letusan G. Krakatau pada bulan agustus Tahun 1883 melahirkan gelombang tsunami yang merambat hingga ke Tangerang, maka pesisir utara di provinsi ini masuk kedalam wilayah yang terancam. Menurut catatan sejarah, gelombang tsunami bahkan mencapai pantai Jakarta dengan tinggi gelombang yang melebihi maksimum alat pengukur tinggi gelombang, dimana pada saat itu tercatat tinggi gelombang rata-rata di Tanjung Priuk adalah 3 meter setelah pengukur tinggi gelombang terbaca kembali (PVMBG, 2014).

Berdasarkan pola ruang RTRW Provinsi Banten, kawasan budidaya yang masuk ke dalam kelas kerawanan banjir "tinggi" adalah kawasan industri, pemukiman, dan pertanian dengan luas masing-masing 53.33\%, 12.01\%, dan $25.91 \%$ dari luas masing-masing peruntukan pola ruang. Pengembangan kawasan budidaya yang potensial 
terhadap banjir seharusnya dikembangkan dengan konsep pembangunan yang tahan terhadap air (mitigasi secara fisik), seperti pembangunan infrastruktur yang memadai maupun perencanaan berbasis bencana alam. Sementara pada zona rawan tsunami, kawasan industri merupakan kawasan budidaya yang memiliki luasan yang paling besar pada kelas kerawanan "tinggi" dan "sangat tinggi". Di wilayah penelitian, kawasan industri sebagian besar terpusat di pesisir bagian utara. Meskipun secara teori kawasan ini relatif jauh dari zona subduksi namun secara history kawasan ini pernah dilanda gelombang tsunami akibat letusan G. Krakatau. Karena itu, ada baiknya jika pola ruang yang diperuntukkan untuk kawasan industri di pesisr utara dikembangkan dengan tetap memperhatikan kawasan rawan bencana tsunami. Sementara untuk kawasan industri yang telah dikembangkan seperti pabrik semen, industri farmasi dan kimia sebaiknya membangun tanggul-tanggul pemecah ombak (wave breaker) sebagai alat yang mampu mereduksi besar gelombang yang masuk ke daratan.

\section{SIMPULAN}

1. Geoindikator penilai rawan banjir dan tsunami berbasis ekoregion ini mencakup bentuklahan, ekosistem, dan komunitas vegetasi. Dari ketiga geoindikator tersebut bentuklahan memiliki bobot paling tinggi dibandingkan dengan ekosistem dan komunitas vegetasi, karena mampu memberikan informasi kerawanan bencana berdasarkan aspek morfologi maupun proses pembentukannya.

2. Kerawanan banjir dan tsunami di daerah penelitian, dibagi kedalam 5 kelas yaitu sangat rendah, rendah, sedang, tinggi, dan sangat tinggi. Zona kerawanan banjir dan tsunami terkonsentrasi pada dataran fluvial dan fluvio-marin, dengan ekosistem vegetasi air tawar pamah dan ekosistem vegetasi air masin.

3. Analisis zona bahaya banjir dan tsunami di daerah penelitian dibagi ke dalam 3 kelas yaitu rendah, sedang, dan tinggi. Hasil uji akurasi zona bahaya banjir menunjukkan nilai nilai kappa yang agak rendah. Sementara peta bahaya tsunami cukup memberikan informasi yang jelas mengenai probabilitas wilayah bahaya bencana.

\section{DAFTAR PUSTAKA}

Aksoy, H., V.S.O. Kirca, H.I. Burgan and D. Kellecioglu. 2016. Hydrological and hydraulic models for determination of flood-prone and flood inundation areas. Proc. IAHS., 137-141. Doi: 10.5194/piahs373-137-2016.

Ayala, I.R. 2002. Geomorphologhy, natural hazards, vulnerability and prevention of natural disasters in developing countries. Geomorp., 47: 107-124. Doi: 10.1016/S0169-555X(02)00083-1.

[BNPB] Badan Nasional Penanggulangan Bencana. 2015. Data Informasi Bencana Indonesia 2015 [Internet]. Tersedia pada http://dibi.bnpb.go.id/ .
Cankaya, Z.C., M.L. Suzen and A.C. Yalciner. 2016. A new GIS-based tsunami risk evaluation: MeTHuVA (METU tsunami human vulnarebility assessment) at Yenikapi, Istanbul. Earth, Planets and Space, 68: 133. Doi: 10.1186/s40623-016-0507-0.

Chaturvedi, R. and S.D. Mishra. 2015. Geomorphic features and flood susceptibility zones: a study for Allahabad District, Utar Pradesh, India, using remote sensing and GIS technique. Trans. Inst. Indian Geographers, 37: 259-268.

Foody, G.M. 2002. Status of land cover classification accuracy assessment. Remote Sens Environ., 80: 185-201. Doi: 10.1016/S0034-4257(01)00295-4

Kartawinata, S. 2013. Diversitas Ekosistem Alami Indonesia. LIPI.

[KLH] Kementerian Lingkungan Hidup. 2013. Deskripsi Ekoregion Nasional. Kementrian Lingkungan Hidup, Deputi Tata Lingkungan, Jakarta.

Khodadad, S. and D.H. Jang. 2015. A comparative study of analytical hierarchy process and ordinary least square methods for landslide susceptibility mapping using gis technology. TOJSAT [internet]. [diunduh 2016 Feb 06]; 5: 7-15. Tersedia pada www.tojsat,.net

Landis, J.R. and G.G. Koch. 1977. The measurement of observer agreement for categorical data. Biometrics J., 33: 159-174. Doi: 10.2307/2529310.

Mudin, Y., F. Ende and H.M. Rusydi. 2015. Spatial analysis on the location of potential danger of flooding in regency of donggala using analytical hierarchy process (AHP). Gravitasi, 14: 75-82.

[NGDC/WDS] National Geophysical Data Center/ World Data Service. 2016. Global Hystorical Tsunami Database. National Geophysical Data Center, NOAA. Doi: 107289/v5pn93h7.

Othman, A.N., W.M. Naim and N. Surip. 2011. GIS based multi-criteria decision making for landslide hazard zonation. Procedia, 35: 595-602. Doi: 10.1016/j.sbspro.2012.02.126.

[PVMBG] Pusat Vulkanologi dan Mitigasi Bencana Geologi. 2014. Gerakan Tanah. PVMBG, Bandung.

Saaty, T.L. 1977. A scalling method for priorities in hierarchical structures. J. Math. Psycol., 15: 234281. Doi: 10.1016/0022-2496(77)90033-5.

Sambah, A.B. and F. Miura. 2014. Integration of spatial analysis for tsunami inundation and impact assessment. J. Geo. Informat. Syst., 6: 11-22. Doi: 10.4236/jgis.2014.61002. 
Santangelo, N., A. Santo, D. Crescenzo, G. Foscari, F. Liuzza, S. Sciarrotta and V. Scorpio. 2011. Flood susceptibility assessment in a highly urbanized alluvial fan: the case study of Sala Consilina (southern Italy). Nat. Hazards Earth Syst. Sci., 11: 2765-2780. Doi: 10.5194/nhess-11-2765-2011.
Sriyono. 2014. Geologi dan Geomorfologi Indonesia. Ombak, Yogyakarta.

Suharini, E. dan A. Palangan. 2014. Geomorfologi: Gaya, Proses dan Bentuk Lahan. Ombak, Yogyakarta. 